\title{
Prevalence of smoking and perceived health problems among male population of Dharan municipality.
}

Poudel S', Gurung DK ${ }^{2}$

${ }^{1}$ Sabitra Poudel, Lecturer, B.Sc. Nursing Department, Kathmandu Medical College, Kathmandu, Nepal; ²Dammar Kumari Gurung, University College London Hospital, Heart Hospital, London, United Kingdom.

\section{Abstract}

Background: Smoking accounts for $8.8 \%$ of annual deaths worldwide. It is practiced by about a third of world population aged 15 years or older. About $73 \%$ of these smokers are in developing countries with overall prevalence in Nepal ranging from $25 \%$ to $73 \%$ in adult men.

Objectives: To assess the prevalence of smoking among the male population, identify the perceived health problems, association between smoking status and selected variables and association between smoking status and existing health problems among respondents.

Methods: A descriptive cross-sectional study was conducted using systematic random sampling among male population of Dharan municipality. The sample size was 180.

Results: This study revealed that the prevalence of smoking was $41.7 \%$. Sixty eight percentage of the respondents had started smoking at the age of 11 to 20 years and most of them initiated smoking due to peer pressure. Forty three percentage of former smokers and $52 \%$ of current smokers had experienced different kinds of health problems like cough and troubled breathing which they perceived as smoking related. A total of $64 \%$ of former smokers had quitted smoking due to health problems. Respondents with low educational status were more smokers $(p<0.05)$, those who were unemployed and if employed then unskilled/semi skilled workers were more smokers $(p<0.01)$. Current smokers experienced more health problems like cough and troubled breathing than non smokers $(p<0.01)$.

Conclusion: This study shows that young people are more vulnerable to start cigarette smoking so there should be frequent positive reinforcement of antismoking campaign focusing more on youth and as well the smoking advertisements should be discouraged.

Key words: Cough, Smokers, Smoking, Troubled breathing

\section{INTRODUCTION}

moking is an addiction. Tobacco contains nicotine $\checkmark$ that is addictive and it contains more than thousand chemicals among which 401 are poisonous substances like cyanide and 43 are carcinogenic ${ }^{1}$.

\footnotetext{
Address for correspondence

Sabitra Poudel

Lecturer

B.Sc. Nursing Department

Kathmandu Medical College, Kathmandu, Nepal.

Email: sabitra.poudel7@gmail.com
}

Smoking harms not just the smoker but also family members, co-workers and others who inhale the smoke (i.e. second-hand smoking). Among children up to 18 months of age second-hand smoke is associated with as many as 300,000 cases of bronchitis and pneumonia each year. It also increases child's chances for middle ear problems, coughing, wheezing and worsens asthma². The first conclusive evidence on the danger of secondhand smoking came from Takeshi Hirayama's study in 1981 on lung cancer in non-smoking Japanese women married to men who smoked ${ }^{3}$.

Smoking is practiced by about a third of world's population aged 15 years or older. About $73 \%$ of these smokers are in developing countries. Globally $48 \%$ 
of men smoke whereas for women it accounts $22 \%$ in developed countries and $9 \%$ in developing countries Almost six million people die from tobacco use each year, both from direct tobacco use and second-hand smoke. By 2020, this number will increase to 7.5 million, accounting for $10 \%$ of all deaths. Smoking is estimated to cause about $71 \%$ of lung cancer, $42 \%$ of chronic respiratory disease and nearly $10 \%$ of cardiovascular disease. The highest incidence of smoking among men is in lower-middle-income countries; for total population, smoking prevalence is highest among upper-middleincome countries ${ }^{4}$.

A study done in different ecological regions of Nepal indicated that prevalence of tobacco use in adults was $68.4 \%$ in rural Kathmandu, $37.0 \%$ in urban Kathmandu, $54.7 \%$ in Terai region and $77.7 \%$ in mountain region. It was interesting to note that in the mountain region, the female smoking rate was $71.6 \%$, which is one of the highest reported in the world 5 .

The overall smoking prevalence in Nepal ranges between $25 \%$ to $73 \%$ in adult men and between $0.8 \%$ to $60 \%$ in adult women across the different regions in the country ${ }^{6}$. Prevalence of smoking in Sunsari is $17 \%{ }^{6}$. These figures indicate the magnitude of the problem and call for attention by health care professionals.

Smoking is responsible for $90 \%$ of all lung cancers, $75 \%$ of chronic bronchitis and emphysema and $25 \%$ of cases of Ischemic heart disease. Forty seven percentages of male cancer deaths and $14 \%$ of female cancer deaths are attributable to smoking. Teenage smokers suffer from shortness of breath almost three times as often as teens who do not smoke, and produce phlegm more than twice as often as teens who do not smoke ${ }^{7}$.

Nepal has very high prevalence rate of chronic obstructive lung disease (COLD) varying from $20-40 \%$ in persons above the age of twenty years. This was found to be significantly associated with tobacco smoking ${ }^{8}$. Acute respiratory infection is the second biggest killer of infants and children in Nepal and positive correlation between tobacco smoking by parents and $A R I$ in infants have been shown in a study conducted in $\mathrm{Nepal}^{9}$. Tobacco smoking has also been found to be associated with coronary artery disease in a hospital-based study in Nepal ${ }^{10}$.
The changing demographic pattern of smoking particularly the unfavourable smoking patterns among younger population may contribute substantially to future burden of smoking related illnesses. To take effective action, it is essential to know the magnitude and patterns of problem and till date no research has been conducted in Dharan regarding prevalence of smoking among the males so our study aims to explore the prevalence of smoking among male population and their perceived health problems as well as the quitting measures used by former smokers and also to identify the association between smoking status and selected variables and association between smoking status and existing health problems among respondents. It also aids data for health action and serves as the documentation for future tobacco control activities.

\section{METHODS}

Descriptive cross-sectional research design was adopted for the study. This study was conducted among male population of Dharan Municipality in eastern Nepal. Males aged 15 years and above were the study population and the Sample size was 180 on the basis of known prevalence rate $50 \%^{5}$ and allowable error $15 \%$. From 19 wards of Dharan three wards were selected by simple random method (lottery method without replacement) which represented $15 \%$ wards of Dharan and total number of houses in each selected wards were identified from the municipality record section and it was 1650. Numbers of houses to be taken from each ward were calculated proportionately. Data was collected by using systematic sampling technique i.e. every ninth house was taken. Only one male meeting the eligibility criteria was taken from one house as study participant. . If more than one was found then only one was selected randomly (lottery method). An interview schedule was used for data collection which consisted of demographic information (for calculating socio-economic status modified Kuppuswamy ${ }^{11}$ scale was used), questionnaire regarding smoking habit (used only for the smokers) and questionnaire for perceived health problems. Content validity of the tool was established with the help of review of literature and teacher consultation and guidance. Questionnaire was translated in Nepali for effective communication with respondents and it was also helpful to maintain reliability. The pre-test was conducted in $\mathrm{G}_{2}$ type staff quarter of B.P. Koirala Institute of Health Sciences (BPKIHS). The sample size was $10 \%$ of total sample. No 
modification was required. Data was analyzed by using Statistical Package for Social Sciences (SPSS), different descriptive and inferential statistics were calculated as shown in findings.

\section{Operational definition of variables:}

Smokers: Men who inform that they have been smoking regularly at least for one year. Former smokers: Men who inform that they have smoked in past and quitted at least for one year. Non-smokers: Men who inform that they have never smoked.

\section{RESULTS}

Table 1 shows that the prevalence of smoking, where smokers were 75 (41.7\%), non smokers 68 (37.8\%) and former smoker 37 (20.5\%).

Majority of respondents (33.9\%) belonged to the age group $15-25$ years where $49.2 \%$ were smokers and $50.8 \%$ were non smokers whereas majority of former smoker belonged to age group 36-45 years. Most of the respondents were educated up to certificate level. Regarding occupation $43.6 \%$ students, $58.4 \%$ unemployed and $55.0 \%$ unskilled and semiskilled workers were smokers whereas majority of skilled people were former smokers.

Majority of the respondents were from lower and upper lower socio economic class. Whereas in upper middle and above seventy percent of the respondents were smokers. Most of the respondents (55.5\%) were Mongolian but only $39 \%$ of them were smokers. Among Aryan majority of them (51.7\%) were smokers. Most of the respondents (65.5\%) were Hindu and among them $44.3 \%$ were smokers. Majority of the respondents $(40.2 \%)$ smoked less than five cigarettes per day where as $6.4 \%$ smoked more than 20 cigarettes per day.

Table 2 shows that Majority (68.8\%) of smokers (former as well as current) had started smoking at the age of 11-20 years [mean \pm SD $(17.45 \pm 5)$ years]. Majority of respondents $(73.2 \%)$ had started cigarette smoking due to peer pressure and $89.3 \%$ had continued due to habituation. Presence of other smokers (22.5\%) had provoked them to smoke more. Twenty one percentage of the current smokers had positive family history of smoking. Almost all i.e. $96 \%$ of current smokers felt that they need to quit smoking.

Around $65 \%$ of smokers had the history of temporary cessation of smoking. Among them $22.1 \%$ had quitted for more than one month to six months followed by less than one week (20.6\%). Though they have ceased temporarily they could not continue the cessation and restarted. Craving for cigarette $(37 \%)$ had been the main reason for the failure to quit smoking habit. Peer pressure and difficulty in concentration were the other reasons behind restarting smoking.

Table 3 shows the presence of health problems where $43.2 \%$ of former smokers had experienced health problems during the course of smoking where all of them had troubled breathing, $62.55 \%$ had cough and $43.7 \%$ were easily tired. They perceived that problems were due to smoking habit and also they had experienced gradual reduction in those problems after quitting.

Similarly, $52 \%$ of current smokers were having health problems out of which $61.5 \%$ were easily tired $43.5 \%$ had cough and $41 \%$ had troubled breathing and they felt that these problems are related to their smoking habit.

The main reason for quitting smoking among former smokers was health problems i.e. $65 \%$ followed by advices from health personnel (16.2\%) and advice from parents/children. The quitting measures applied by former smokers were cold turkey method i.e. all at once $(44.6 \%)$ followed by replacement with other substances (32.5\%).

Table 4 shows that there is association between smoking status and selected variables. Those who were educated only up to primary level were more smokers. Regarding occupation unskilled/ semi skilled workers smoked more thus it shows that there is association between smoking and level of education and occupation as well.

Table 5 shows that there is association between existing health problems and smoking status where smokers had more health problems like troubled breathing, cough and easily tired than non smokers. 
Table 1: Demographic Characteristics of Respondents ( $n=180)$

\begin{tabular}{|c|c|c|c|c|}
\hline Variables & $\begin{array}{c}\text { Smokers } \\
\text { Number (\%) }\end{array}$ & $\begin{array}{c}\text { Non smokers } \\
\text { Number (\%) }\end{array}$ & $\begin{array}{c}\text { Former smokers } \\
\text { Number (\%) }\end{array}$ & $\begin{array}{c}\text { Total } \\
\mathrm{n}=180\end{array}$ \\
\hline Smoking status & $75(41.7)$ & $68(37.8)$ & $37(20.5)$ & 180 \\
\hline \multicolumn{5}{|l|}{ Age (years) } \\
\hline $15-25$ & $30(49.2)$ & $31(50.8)$ & - & 61 \\
\hline $26-35$ & $28(47.5)$ & $24(40.7)$ & $7(11.8)$ & 59 \\
\hline $36-45$ & $8(27.6)$ & $6(20.7)$ & $15(51.7)$ & 29 \\
\hline $46-55$ & $4(28.6)$ & $4(28.6)$ & $6(42.8)$ & 14 \\
\hline $56-65$ & $4(33.3)$ & $2(16.7)$ & $6(50.0)$ & 12 \\
\hline$>65$ & $1(20.0)$ & $1(20.0)$ & $3(60.0)$ & 5 \\
\hline \multicolumn{5}{|l|}{ Education } \\
\hline Illiterate & $4(57.1)$ & $1(14.3)$ & $2(28.6)$ & 7 \\
\hline Primary & $13(37.2)$ & $4(11.4)$ & $18(51.4)$ & 35 \\
\hline Secondary/certificate & $45(42.8)$ & $49(46.7)$ & $11(10.5)$ & 105 \\
\hline Graduate/post graduate & $13(39.4)$ & $14(42.4)$ & $6(18.2)$ & 33 \\
\hline \multicolumn{5}{|l|}{ Occupation } \\
\hline Student & $17(43.6)$ & $19(48.7)$ & $3(7.7)$ & 39 \\
\hline Unemployed & $14(58.4)$ & $8(33.3)$ & $2(8.3)$ & 24 \\
\hline Unskilled/semi skilled & $28(55.0)$ & $12(23.5)$ & $11(21.5)$ & 51 \\
\hline Skilled/professionals & $16(24.2)$ & $29(44.0)$ & $21(31.8)$ & 66 \\
\hline \multicolumn{5}{|l|}{ Socio-economic status } \\
\hline Lower and upper lower & 46 (39.3) & $45(38.5)$ & $26(22.2)$ & 117 \\
\hline Lower middle & $22(41.5)$ & $20(37.7)$ & $11(20.8)$ & 53 \\
\hline Upper middle and above & $7(70.0)$ & $3(30.0)$ & - & 10 \\
\hline \multicolumn{5}{|l|}{ Ethnicity } \\
\hline Aryan & $15(51.7)$ & $11(38.0)$ & $3(10.3)$ & 29 \\
\hline Mongolian & $39(39.0)$ & $42(42.0)$ & $19(19.0)$ & 100 \\
\hline Others & $21(41.2)$ & 15 (29.4) & 15 (29.4) & 51 \\
\hline \multicolumn{5}{|l|}{ Religion } \\
\hline Hindu & $51(44.3)$ & $41(35.7)$ & $23(20.0)$ & 115 \\
\hline Kirat & $12(36.4)$ & $14(42.4)$ & $7(21.2)$ & 33 \\
\hline Buddhist & $9(45.0)$ & $8(40.0)$ & $3(15.0)$ & 20 \\
\hline Christian & $3(25.0)$ & $5(41.6)$ & $4(33.4)$ & 12 \\
\hline
\end{tabular}

Table 6 shows the respondent's perception regarding smoking related health hazards where $94 \%$ smoker, 95.5\% non smoker and $91.8 \%$ former smoker perceived that smokers are more prone to have health hazards. All smokers, non smokers and $97.1 \%$ former smokers felt that smokers would suffer from troubled breathing. Majority of the smokers (98.6\%), all non smokers and $94.1 \%$ former smokers perceived that smoking can cause cough. Regarding illnesses most of them perceived that smoking causes cancer and asthma and heart disease. 
Table 2: Distribution of Respondents Regarding Smoking Related Factors $(n=112)$

$\begin{array}{lr}\text { Factors } & \text { Number (\%) } \\ \text { Started age } & \\ \text { Below } 10 \text { years } & 77(68.9) \\ 11-20 \text { years } & 19(17.0) \\ 21-30 \text { years } & 6(5.3) \\ >30 \text { years } & \\ \text { *Reasons for initiation of smoking } & \\ \text { Curiosity } & 15(13.4) \\ \text { Peer pressure } & 82(73.2) \\ \text { To become smart } & 7(62.5) \\ \text { To relieve tension } & 5(4.5) \\ \text { For enjoyment } & 6(5.3) \\ \text { Imitating parents } & 9(8.0) \\ \text { Others } & 15(13.4) \\ \text { *Reasons for continuing smoking. } & \\ \text { To relieve tension } & 4(3.6) \\ \text { For enjoyment } & 9(8.0 \\ \text { Habituated } & 100(89,3) \\ \text { Others. } & 2(1.8) \\ \end{array}$

Table 3: Presence of Health Problems among Smokers and former smokers

\begin{tabular}{|c|c|}
\hline $\begin{array}{l}\text { Presence of Problems among former } \\
\text { smokers }(n=37)\end{array}$ & $\begin{array}{c}\text { Number } \\
(\%)\end{array}$ \\
\hline Yes & $16(43.2)$ \\
\hline No & $21(56.8)$ \\
\hline \multicolumn{2}{|l|}{ Health problems present ${ }^{*}(n=16)$} \\
\hline Troubled breathing & $10(62.5)$ \\
\hline Cough & $7(43.7)$ \\
\hline Easily tired & $1(6.25)$ \\
\hline Headache & $3(18.7)$ \\
\hline Others & $16(100.0)$ \\
\hline \multicolumn{2}{|l|}{$\begin{array}{l}\text { Presence of problems among current } \\
\text { smokers }(n=75)\end{array}$} \\
\hline Yes & $39(52.0)$ \\
\hline No & $36(48.0)$ \\
\hline \multicolumn{2}{|l|}{ Health problems present ${ }^{*}(n=39)$} \\
\hline Easily tired & $24(61.5)$ \\
\hline Troubled breathing & $16(41)$ \\
\hline Cough & $17(43.5)$ \\
\hline Headache & $6(15.4)$ \\
\hline Others & $5(11.2)$ \\
\hline
\end{tabular}

*note: multiple response

Table 4: Association between Smoking Status and Selected Variables $(n=143)$

$\begin{array}{lccc}\text { Variables } & \text { Smokers } & \text { Non smokers } & \text { p value } \\ \text { Education } & & & \\ \text { Up to primary } & 17 & 5 & <0.05 \\ \text { Secondary to certificate } & 45 & 49 & \\ \text { Graduate/post graduate } & 13 & 14 & \\ \text { Occupation } & & & \\ \text { Student } & 17 & 8 & <0.01 \\ \text { Unemployed } & 14 & 12 & \\ \text { Unskilled/semi skilled worker } & 28 & 29 & \\ \text { Skilled/ professional } & 16 & & \\ \text { Socio-economic status } & & 45 & >0.05 \\ \text { Lower/upper lower } & 46 & 20 & \\ \text { Lower middle } & 22 & 3 & \\ \text { Upper middle \&above } & 7 & \end{array}$


Poudel S et al.

Table 5: Association between existing health problems and smoking status $(n=143)$

\begin{tabular}{|c|c|c|c|}
\hline Health Problems & Smokers & Non-smokers & $p$ value \\
\hline \multicolumn{4}{|l|}{ Troubled breathing } \\
\hline Present & 16 & 4 & $<0.01$ \\
\hline Absent & 59 & 64 & \\
\hline \multicolumn{4}{|l|}{ Cough } \\
\hline Present & 17 & 5 & $<0.01$ \\
\hline Absent & 58 & 63 & \\
\hline \multicolumn{4}{|l|}{ Easily tired } \\
\hline Present & 21 & 6 & $<0.01$ \\
\hline Absent & 54 & 62 & \\
\hline \multicolumn{4}{|l|}{ Headache } \\
\hline Present & 6 & 3 & $>0.05$ \\
\hline Absent & 69 & 65 & \\
\hline
\end{tabular}

Table 6 : Perceived health hazards caused by smoking $(n=180)$

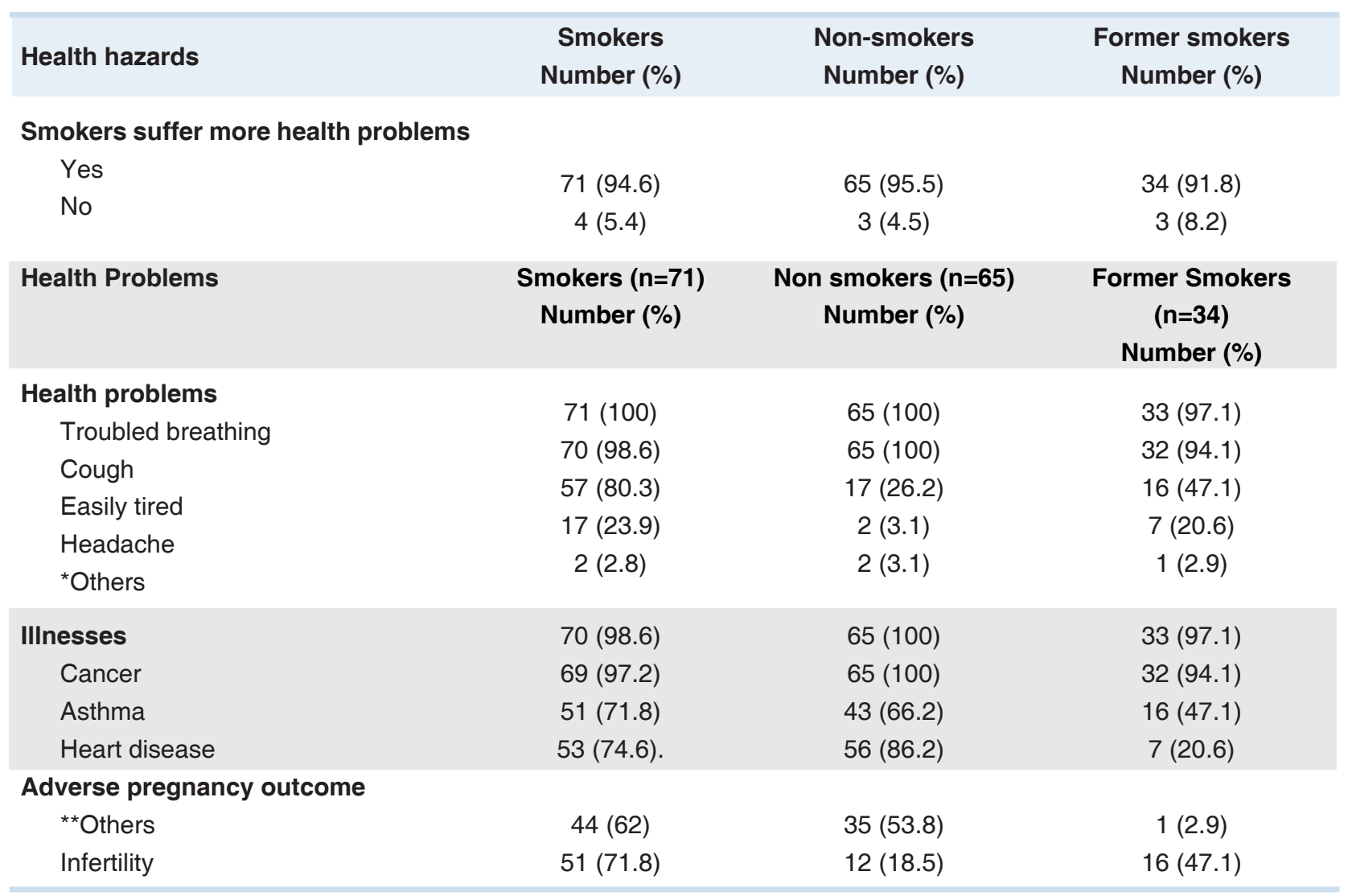

*Low birth weight, premature delivery,backache, vision problem

** Tuberculosis, stroke 


\section{DISCUSSION}

Smoking is responsible for considerable number of morbidity and mortality in the world. It is one of the most important preventable risk factor of most non communicable diseases. Every year tobacco causes $8.8 \%$ i.e. 4.9 million deaths worldwide ${ }^{12}$.

Smoking has been associated with many negative health effects and quitting smoking helps to reduce the risks of developing later health problems.

This study was conducted with the purpose to find out the prevalence and perceived health problems among the male population of Dharan. Almost $50 \%$ of respondents from age group 15 to 25 smoked which is almost similar to finding of a national health survey on tobacco consumption ${ }^{13}$ which showed that among 15-19 years age group prevalence of ciggerate smoking was $10.8 \%$ and among 20 to 24 years it was $25.3 \%$.

Only $21 \%$ of the current smoker had the family history of smoking which highlights that family history doesn't play vital role in the smoking status.

This study revealed that majority of the smokers (68.8\%) had started smoking at the age of 11 to 20 years (mean $=17.45 \pm 5.8$ ) which is consistent with the global youth tobacco survey in $\mathrm{Nepal}^{5}, 1990$, reported that $93.0 \%$ of all daily smokers had started smoking before the age of 20 years. Among them $27.0 \%$ of smokers had started before the age of 15 years.

Regarding the initiation of smoking, most of the smokers $(59.0 \%)$ had started smoking due to peer pressure, followed by curiosity $(10.8 \%)$, this finding is consistent with the study ${ }^{14}$ conducted in turkey, which reported that friends were the most frequent source for the first cigarette for both the boys (49.1\%) and girls (34.6\%). Nearly two - thirds of youth $(62.6 \%)$ had tried their first cigarette with their friends, study had shown that the likelihood of adolescent starting smoking increases three fold when they associate themselves with friends who promote smoking experimentation. this finding is also supported by the study ${ }^{15}$ done in Oklahoma which revealed that having friends who smoke is the principal predictor of smoking. To have a smoker as the best friend increases significantly the probability of smoking (odds ratio: 6.96, 95\% confidence intervals (Cl) (4.93 to 9.84), and the same stands for one smoker living at home compared with a smoking free home (odds ratio: $2.03,95 \% \mathrm{Cl} 1.22$ to 3.36$)^{16}$. This finding is consistent with the study ${ }^{14}$ conducted in turkey which reported that one smokes more when encouraged by others, to reduce stress and anxiety and to solve the problems. This finding indicates that smoking is perceived and adopted as a way of problem solving and coping with stress. Regarding the continuation of smoking the study findings showed that majority of the respondents $(87.0 \%)$ had continued smoking due to habituation. This is supported by the findings of a study ${ }^{17}$ which reported that smokers continued smoking as a result of addiction of nicotine which is psychologically and physically addicted and one is habituated smoking due to addiction.

This study revealed that $96 \%$ of the current smokers felt the necessity for quitting smoking. Among them, 65.1\% had the history of temporary cessation of smoking. Majority of them had quit for one month to six months (22.1\%) followed by up to one week (20.6\%). Most of the adolescents had quit temporarily for four to five months for the recruitment in the British Army and restarted after the recruitment or failure to recruit. This finding is supported by a study ${ }^{18}$ on effectiveness of smoking cessation programme revealed that $75-80 \%$ of smokers want to quit and about one-third have made at least three serious attempts to do so. In spite of these desires and efforts less than 50\% succeed in stopping tobacco permanently. This is also similar to the finding of a study ${ }^{19}$ which showed relapse rates were much larger than expected in the early days and weeks after the quit attempt. Approximately $62 \%$ had relapsed by 2 weeks after their quit dates. Regarding the restarting of smoking who had quitted for certain duration, craving for cigarette was the main reason $(37.0 \%)$ followed by peer pressure. This finding is consistent with the study ${ }^{20}$ Concerns about health are the most common reason patients give for quitting, and addiction is the most important barrier to quitting. Education, social pressure, provider advice, and formal programs, but not overthe-counter devices, appear to increase the chances that smokers will quit. Most of the smokers had health problems like cough, troubled breathing, early tiredness etc..during the course of smoking, also they felt that these problems are related to smoking. This findings are consistent with findings of a study ${ }^{21}$ which depicted that smoking in adolescence is associated with suboptimal self perceived health and health problems in adolescent. 
Boys who smoked daily were more frequently users of medication for cold symptoms compared with non smokers, it is similar with a study ${ }^{22}$ which reported that daily smoking among both sexes and all age group was associated with significantly poorer perceived health, respiratory symptoms, headache, neck and shoulder pain, stomachache, frequent heartburn, restlessness and sleep problems but contradicted by another study ${ }^{23}$ which revealed that smokers perceived their health risks was either not at all or only slightly affected by smoking and almost half of the smokers thought that quitting would bring either no benefit or only minor benefit to their health.

This study findings show that majority of the former smokers $(64 \%)$ had quitted smoking due to health problem followed by advice from the health personnel. this finding is consistent with the study ${ }^{24}$ which reported that experiences of chest pain, suffering from cardio vascular disease and respiratory diseases had influenced quitting attempts. A study ${ }^{25}$ showed that when nurses offered smoking cessation advice and intervention, patients were more likely to quit than when nurses offered no intervention at all. Another study ${ }^{26}$ showed that health concerns were the motive for all former smokers to quit. This study revealed that majority of the former smokers $(44.6 \%)$ had quitted all at once (cold turkey) followed by replacement with other substances (32.3\%) like pan supari, clove and cutting down slowly (scheduled reduction $12.3 \%$ contradictory to the finding of a study ${ }^{26}$ reported that only about four percentages of smokers who quit without any outside help (cold turkey) succeeded, scheduled reductions were twice as likely to quit as those who went cold turkey and men who had quitted for 10 years with those who failed found that those who substituted with other types of oral behaviors were more likely to succeed in quitting than those who did not.

The study depicted that there is association between smoking status and education $(p<0.01)$. It showed that among the subjects, who were educated up to primary level, majority of them (77\%) were smokers. It showed that people who were less educated were smokers. Result of national health survey ${ }^{10}$ depicted that in Uchha Phahadi Pradesh $84.7 \%$ men smoked and $71.7 \%$ of the women, whereas in urban Kathmandu $64.5 \%$ of the men smoked and only $14.2 \%$ of the women. Prevalence tended to decrease with educational status.
The study findings show that there is association between smoking status and occupation $(p<0.01)$. It showed that people who were unemployed and if employed, working as unskilled/semi skilled workers were more smokers. Unemployed might smoke more due to tension of being unemployed and leisure time whereas for unskilled/semi skilled worker they were more likely to find themselves in conditions predisposing themto initiation of smoking and chewing. This study depicted that there is no association between socio-economic status which is contradicted by a study ${ }^{27}$ which reported that there is a solid evidence that lower socio-economic status is associated with higher likelihood of smoking.

This study revealed that there is association between smoking status and existing health problems such as troubled breathing, cough and easily tiredness $(p<0.01)$ whereas there is no association between smoking status and headache. This is consistent with the study ${ }^{10}$ that smokers were nearly twice as likely to suffer from any health problem compared to non smokers. A global tobacco youth survey showed that Nepal has high prevalence rate of COPD from $20-40 \%$ in persons above the age of 20 years, this was found to be significantly associated with tobacco smoking. Same study also showed that tobacco smoking has also been found to be associated with coronary artery diseases. A study ${ }^{28}$ revealed that even very light smoking is found to increase the incidence of myocardial infarction as mortality and morbidity from coronary heart disease depends on the short term thrombogenic effect of tobacco smoke constituents and not on accumulated exposure. Study revealed that majority of the current smokers (94.6\%) believed that smokers are more prone to suffer from more health problems than non smokers. Those smokers who had been smoking since years and apparently well till then did not believe with it.

This study depicted that all smokers, all non smokers and $97.1 \%$ former smokers thought that smokers would suffer from troubled breathing. Most of the subjects also thought that smokers would suffer from cough and easily tiredness. Regarding illnesses most of them perceived that smoking causes cancer (lung, throat, oral, tongue) and asthma. Around half of them thought that it can also lead to heart disease. Majority of the smokers and non smokers whereas few former smokers thought that 
smoking causes adverse pregnancy outcome. Only few said that it can cause infertility. It indicates that a substantial majority of the respondents recognize the general health, tuberculosis, risk of cancer lung, heart disease and adverse pregnancy outcomes (prematurity, low birth weight, still birth) where as fewer know that it can lead to infertility. According to study ${ }^{29}$ conducted to assess the knowledge and perceived risk of smoking or smoke related conditions on 537 adult treatment seeking smokers, average percentage of knowledge items correct for each disease category included: cardiovascular $95.0 \%$, pulmonary $94.0 \%$, oral health problems $89.0 \%$, smoking related cancer $71.0 \%$ and reproductive risk $44.0 \%$. In the same study, premature death was identified as a risk by $95.0 \%$ of smokers, yet only $63.5 \%$ reported that disability could also result from smoking.

According to national health survey ${ }^{10}$ in tobacco control

\section{REFERENCES}

1. Roemer R. Legislative action to combat the world tobacco epidemic. $2^{\text {nd }}$ ed.Geneva: WHO ; 1993.48$9 p$

2. United States Environmental Protection Agency.. Respiratory Health Effects of Passive Smoking: Lung Cancer and Other Disorders .[Internet].1992 [cited 2006 June 21]. Available from: http://www.epa.gov/smokefree/healtheffects. $\mathrm{html}$

3. WHO. Passive Smoking. [Internet].1981 January [cited 2006 June 21]. Available from: http://www.who.int/ tobacco/en/atlas10.pdf

4. World Health Organisation. Tobacco or health: a global status report. Geneva: World Health Organization; 1997.12-3p

5. Pandey MR, Pathak R. Challenges of tobacco use behavior in central development region of Nepal: Global Youth Tobacco Survey Collaborative Group Nepal GYTS Fact Sheet.[Internet]. 2002 [cited 2005 October 10]. Available from: http:/ /www. cdc.gov/tobacco/global/GYTS/reports/searo/2001/ nepal_report.htm .

6. Jha NP, Upadhyaya MP, Lakhey S, Yadav BK, Baral DD, Gautam A. Smoking and smokers in Sunsari. Nepal. J Nep Med Assoc.1999; 38:7-13.

7. Preventing tobacco use among young people:A measures 1993 although a large proportion of adults are now aware of the hazards of smoking, a number of smokers are still not concerned about the effects on their own health or on the health of others.

\section{CONCLUSION}

Male populations of Dharan are actively involved in smoking with prevalence of smoking (41.7\%). There is influence of education and occupation on smoking status which indicates that illiteracy, ignorance and unemployment can lead to smoking. Though most of the smokers are well informed about the health hazards caused by smoking still they are continuing their habit of smoking, so there is need for creating more awareness regarding health hazards of smoking to motivate them to give up their habit of smoking. Since majority of people starts smoking at adolescence, school health programme can be conducted to create awareness among the school children before they start smoking.

report of Surgeon General Atlanta GA US Department of health and human service Centre for disease control. [internet]. 1995 [cited 2006 June 21]. Available from: http://profiles.nlm.nih.gov/NN/ $\mathrm{B} / \mathrm{C} / \mathrm{L} / \mathrm{Q} /$

8. Pandey MR, Basnyat B, Neupane RP. Chronic Bronchitis \& Cor Pulmonale in Nepal.Kathmandu: Mrigendra Samjhana Medical Trust; 1988

9. Pandey MR, Sharma PR, Neupane RP. Parental Tobacco Smoking and Acute Respiratory Infections (ARI) in Nepal. J of Inst. Med. 1991;13:227-38.

10. Pandey MR, Ghimire M. Prevalence of various types of heart diseases in Kathmandu. J Nep Med Assoc. 1975; 13: 37-46.

11. Kumar P. Social classification- need for constant updating. Ind J Comm Medicine. 1993;18(2):60-1.

12. WHO. Tobacco or health: A Global status report. Geneva: WHO; 1997. 3p.

13. MOHP. Nepal Demographic and Health Survey;2006.84p

14. Erbaydar T, Lawrence S, Dagli E, Hayran O, Collishaw NE. Initiation of youth to smoking in Turkey [Internet]. 2005 [Cited 2006 June 18]. Available from http://archive.idrc.ca/ritc/TurkeyYouth

15. Miller $\mathrm{CH}$, Burgoon M, Grandpre JR, Alvaro EM. Identifying principal risk factors for the initiation of 
adolescent smoking behaviours: the significance of psychological reluctance. Health Commun. [Internet]. 2006[cited 2006 Jun 18];19(3):241-52. Aavailable from: http://www.ncbi.nlm.nih.gov/ pubmed/16719727

16. Pinilla J, González B, Barber P, Santana Y.Smoking in young adolescents. J Epidemiol Community Health. 2002 Mar; 56 (3):227-32.

17. Smoke free living. [Internet]. 2006[cited 2006 Jun 14].Available from: http://www.smokefreeliving. net/harmful-effects-of-smoking

18. Vilain C. The Evaluation and Monitoring of Public Action on Tobacco, Smoke -free Europe: Copenhagen :WHO Regional Office for Europe; 1997: 66-7

19. Garvey AJ, Bliss RE, Hitchock JL, Heinold JW, RosnerB.Predicttors of smoking relapse among self-quiters: A report from the normative aging study. Addictive Behaviors.[Internet].1992 [Cited 2006 May 22];17: 367-377. Available from http://whyquit.com/studies/1992Garvey_ LapseEqualsRelapse_95_Percent.pdf

20. Duncan CL, Cummings SR, Hudes ES, Zahnd E, Coates TJ. Quitting smoking: reasons for quitting and predictors of cessation among medical patients. J Gen Intern Med.[internet]. 1992[cited 2006 June 18]; 7(4):398-404.. Available from http:// www.ncbi.nlm.nih.gov/pubmed/1506945/

21. Rius C, Fesnazed E.Schiaffino A, Borra JM, Artalejo FR. Self perceived health and smoking in adolescents. $\mathrm{J}$ Epidemiol Community Health. [Internet].2004 [Cited 2006 Jun 20]; 58:698-699. Available from http://jech.bmj. com/content/58/8/698.extract DOI: 10.1136/ jech.2003.008516

22. Holmen TL, Connor EB, Holmen J, Bjermer L. Health problems of teen age smokers vs non smokers in Norway. American journal of epidemiology .2000; 151 (2):148-55

23. Prokhorov AV, Warneke C, Carla DM, Emmons KM,
Jones MM, Rosenblum C, Hudmon KS, Gritz ER. Self-reported health status, health vulnerability, and smoking behavior in college students: Implications for intervention. Oxford journal. Nicotine\& Tobacco Research. [internet]. 2003 Aug [Cited 2006 May 16];5(4):545-52 Available from http://ntr.oxfordjournals.org/content/5/4/545.short

24. Szanto Z, Susanszky E, Kopp M. Relationships between unfavourable health status and smoking cessation attempts in Hungary. Sozial- und Praventivmedizin. [Internet].2005 [Cited 2006 Jun 18]; 50(5):324-33. Available from: http://www.ncbi. nlm.nih.gov/pubmed/16300177

25. Rice VH,Stead LF. Nursing interventions for smoking cessation. The Cochrane Library. [Internet].2001 May 15 [Cited 2006 Jun 21]. Available from: http:// onlinelibrary.wiley.com/ DOI/10.1002/14651858. CD001188

26. CDC National Center for Chronic Disease Prevention and Health Promotion. Quit to Live: How and Why to Quit Smoking Today. [Internet].2001 [Cited June 12, 2006.Available from: www.cdc. gov/tobacco/news/QuitSmoking.htm

27. Siahpush M,Brown A, Scollo M.Social Inequalities in Smoking. Vic Health Centre for tobacco control. [Internet].2002[Cited 2006 June 20. Available from: http://www.vctc.org.au/publ/reports/social_ inequalities_in_smoking.pdf

28. Peto R, Doll R, Boreham J, Thun M, Heath $H$. Mortality from smoking in developed countries $\mathrm{Br}$ Med Bull.[Internet]. 1996[Cited 2006 May 12].; 52 (1):12-21. Available from: http://bmb. oxfordjournals.org/content/52/1/12.short/DOI 10.1093/oxfordjournals.bmb.a0115

29. Oncken C, McKee S, Krishnan-Sarin S, O'Malley $\mathrm{S}$, Mazure CM. Knowledge and perceived risk of smoking related conditions: A survey of cigarette smokers. Prev Med. [internet]. 2005 Jun [Cited 2006 May 12] ; 40(6):779-84. Available from: http:// www.ncbi.nlm.nih.gov/pubmed/15850879 